http://dx.doi.org/10.12795/PH.1992.v07.i01.10

\title{
EL ISLAM DE BORGES
}

\author{
Emilio G. Ferrín
}

There are eight cornerstones fastening the oriental pages in the writings of Borges: The loneliness of God, The Koran, The world of Thousand Nights and a Night, The empire of Alexander, The poetry of Omar Khayyam, Sindbad the Sailor (the other Ulysses), The Moslem Spain, and some other persian tales. Borges compiles, classifies, assimilates and, at the very end, creates a new world combining different times and geographies, combination that uses to become a singular mixture. 'I should have studied the oriental literatures much harder', states the argentinian in such a modest way that makes the scholar feel some shame. How can we explain his historical preciseness while ha writes? 'It's just -he says-that I felt the stroke, the impact of beauty'.

«Cuentan los hombres dignos de fe (pero Alá sabe más) que en los primeros días hubo un rey de las islas de Babilonia que congregó a sus arquitectos y magos y les mandó construir un laberinto tan perplejo y sutil que los varones más prudentes no se aventuraban a entrar, y los que entraban se perdían. Esa obra era un escándalo, porque la confusión y la maravilla son operaciones propias de Dios y no de los hombres».

Este fragmento no da pie a uno de los innumerables relatos incluidos en las Mil y una noches, ni forma parte de las fábulas que el filósofo Paydeba nos narra en la versión árabe del Calila y Dimna. No es más -ni menos-que el principio de un relato de Jorge Luis Borges («Los dos reyes y los dos laberintos», El Aleph); pero su estructura, sus referencias a Dios y su temática podrían hacerlo pasar por cualquiera de las joyas de la literatura persa-islámica. Y es que Borges es capaz no ya de tratar un tema clásico de cualquier literatura, sino de calcar su espíritu, su estilo; procedimiento que, en el caso de sus relatos «orientales», le acerca a la técnica del romántico Washington Irving. 
Como Irving, como cualquier viajero romántico, -si bien los viajes orientales de Borges suelen ser «bibliotecarios»-, no trata sólo de conocer otros pueblos, otras literaturas, sino de sentirlos en su variopinto colorido de elementos, dogmas, mitos y nombres. Borges recopila, clasifica, asimila y después re-crea combinando tiempos y geografías; combinación que en muchos casos se convierte en mezcla, nunca pastiche, como cuando trata de un modo unitario elementos árabes, islámicos y persas con alguna que otra aportación hindú producto de sus lecturas de Rudyard Kipling. Se diría que, sentado a escribir con sus notas bien ordenadas sobre la mesa, una ráfaga de viento jugó con fechas, nombres y títulos de libros hasta que -en palabras suyas- la obra le confió la forma que buscaba.

Pero siempre, la combinación de la obra de Borges acaba siendo feliz, sin que la ráfaga de viento ordenadora de referencias se convierta nunca en el vendaval de otros estilos parecidos que vemos, por ejemplo, en algunos fragmentos de El péndulo de Foucault de Eco.

Así, en la combinación árabe, islámica, persa o, genéricamente oriental del argentino, se entremezclan una serie de componentes que suelen ser fijos y referidos a ocho campos concretos:

- La soledad de Dios.

- El Corán.

- El mundo de las Mil y una Noches.

- Alejandro Magno (el Iskandar du-l-Qarnayn de la literatura árabe).

- El poeta Omar Jayyam y sus cuartetas (las Ruba'iyat).

- Sindbad (el otro Ulises).

- La España del Islam.

- El elemento estrictamente persa.

$$
* * * *
$$

Ya en Fervor de Buenos Aires (1923) encontramos la primera referencia de Borges al Islam;

«...y la voz de un almuédano

apesadumbra desde su alta torre

el aire de este día

y anuncia a la ciudad de los muchos dioses

la soledad de Dios...».

(«Benarés» Fervor... Vol. I, pág. 40)

Curiosamente, este su primer acercamiento al mundo arabo-islámico coincide con el primer dogma del Islam: «Di, ;Dios es Uno!», reza el Corán en su azora 112. Así, en su re-creación del hecho coránico, Borges empieza por la base, por la soledad de Dios; el anuncio con que el almuédano «apesadumbra desde su alta torre». Es Su soledad lo que 
llama la atención del argentino. O mejor, es Su soledad la que su curiosidad descubre. Porque una mera atención no se para a escudriñar el significado de las palabras con que el almuédano llama a la oración; el modo en que proclama la soledad de Dios varias veces en cinco momentos del día ( Dios es Grande. Doy fe de que no hay más dios que Dios»). Esta soledad de Dios no es sino la profesión de fe islámica.

Desde aquí, salta Borges a otro principio de la fe islámica; el de la Tabla Guardada; el Libro Celesta en que Dios ha escrito con su Cálamo el destino de los hombres. Así, en Discusión (1932), escribe:

«...han resuelto <los musulmanes> que el original del Corán - «la madre del Libro»-es uno de los atributos de Dios, como Su misericordia o Su ira, y lo juzgan anterior al idioma, a la Creación».

$$
\text { (Vol. I, pág. 209) }
$$

Mucho después, en una conferencia sobre «El Libro» (Borges Oral, $4^{\mathrm{a}}$ ed. Barcelona, Bruguera, 1985), amplía la referencia de tal modo que no desluciría en cualquier manual de teología islámica:

«...los musulmanes. Estos piensan que el Corán es anterior a la Creación, anterior a la lengua árabe; es uno de los atributos de Dios, no una obra de Dios; es como su misericordia o su justicia. En el Corán se habla en forma asaz misteriosa de la madre del Libro. La madre del Libro es un ejemplar del Corán escrito en el cielo. Vendría a ser el arquetipo platónico del Corán, y ese mismo libro -lo dice el Corán-, ese libro está escrito en el cielo».

(pág. 17)

Pero es el mundo de las Mil y Una Noches el que más le fascina: libro reconocido de cabecera por muchos de sus personajes (ver Artificios, Vol. I, pág. 527, o El libro de arena, Vol. I, pág. 71), su tratamiento oscila entre lo fantástico y lo riguroso. Borges cree en el mundo de las Mil y Una Noches; la fantasía persa del insomnio, los velos seductores y los relatos eternos; pero ello no le impide llevar a cabo un exhaustivo estudio historiográfico de su traducción a las lenguas occidentales (Historia de la eternidad, Vol. I «Los traductores de las mil y una noches», págs. 397-413).

Es, sin duda, su clave referencial favorita. Todo relato tiene cabida en el libro eterno, de estructura circular. Todo puede incluirse con referencias temporales a cualquiera de esas mil y una noches; admoniciones (Historia de la eternidad, Vol. I, pág. 379), maldiciones ( $l b$, pág. 419), o relatos circulares en los que, como un espejo puesto frente a otro, un narrador se narra a sí mismo narrando (Ficciones, Vol. I, pág. 477).

Las Mil y Una Noches son mucho más que un libro; son la larga fantasía somnolienta del Islam borgeano (El otro, el mismo, Vol. I, pág. 936); son especia, ingrediente ineludible de toda obra no convencional (Siete noches, Vol. I, pág. 211) elaborado por los hechiceros y genios que habitan en sus volúmenes (Los Conjurados, Vol. I, pág. 485), engendrados por el ancho tiempo musulmán: 
«...el tiempo ocioso y generoso de España (el ancho tiempo que engendró las Mil y una noches)».

(Evaristo Carriego, pág. 115)

El Islam y España. Porque para Borges, el elemento islámico es factor constitutivo de la esencia española, junto con el elemento judío y el cristiano:

«España del Islam, de la cábala

y de la Noche Oscura del Alma».

(El otro, el mismo, Vol. I, «España», pág. 931)

Los tres componentes configuran la España trascendente: no es la España de los musulmanes, sino la del Islam; no es la de los judíos, sino la de la cábala; no es el cristianismo, sino la trascendencia de su literatura mística. Esta España, presta su suelo a la geografía del Islam, como en el poema «leones»:

«Leones en el oro y en el verso

En patios del Islam y en evangelios».

(Historia de la noche, Vol.II, pág. 174)

$<$ son, sin duda, los leones del famoso patio de la Alhambra $>$

O como cuando oye las voces y siente la bizarría de una sola palabra, Andalucía:

«La mezquita y el arco. La cadencia

del agua del Islam en la alameda».

(Los Conjurados, Vol. II «De la diversa Andalucía», pág. 491)

*****

La búsqueda de nombres llamativos para sus personajes lleva a Borges a volver sus ojos una vez más hacia lo oriental, seducido especialmente por la sonoridad de la onomástica árabc. Este recurso reviste de exotismo el relato «Las doce figuras del mundo», escrito al alimón con Bioy Casares bajo el seudónimo de H. Bustos Domecq': el doctor Abenjaldún, misteriosamente desaparecido; Abul Hasán (dueño de una flota de camiones), o el tesorero Izadún. (En el mismo relato hacen su aparición otros tres personajes llamados Yusuf, Ibrahim y Jalil).

Generalmente, los nombres propios árabes que emplea pertenecen a personajes históricos reales, aunque a veces el relato no se sitúe en el contexto original del personaje

Nota: Para las citas de libros de Borges, seguimos la edición de sus Obras Completas, 2 vols. Buenos Aires, emecé, 1974. El número romano (I o II) corresponde al volumen, y las cifras árabes a las páginas correspondientes.

Ador ro BuY CASARHS y Jorgit: LuIs Borgis, Los mejores cuentos policiales, 2 vols. Madrid, Alianza/emecé 1985 (I), y 1986 (II). Cfr. pág. 255 y 256. 
en cuestión. Así, en «El acercamiento a Almotasim» (I, 414), el nombre del misterioso Almotasin, ora blasfemo, ora librero persa, pertenece en realidad al califa al-Mu'tasim, octavo de la dinastía 'abbasí; y el Tárik Benzeyad que según el relato borgeano (El Aleph, «El Aleph», Vol. II, pág. 627) halló un espejo en una torre, que el argentino refiere citado en la noche 272 de las Mil y una noches, no es otro que Târiq Ben Ziyâd, el dirigente que inició la conquista (o asentamiento, o invasión) musulmana de España, en el 711.

Un nombre que parece llamar especialmente la atención del argentino es la versión árabe del nombre de Alejandro Magno, Iskandar du-l-Qarnayn, cuya traducción demuestra conocer («Alejandro Bicorne», o «el de los dos cuernos», por la forma que, sobre el mapa, tenía el imperio que conquistó):

«...descubrió en una biblioteca de Santos un manuscrito suyo que versaba sobre el espejo que atribuye el oriente a Iskandar Zu-al-Karnayn ${ }^{2}$, o Alejandro Bicorne de Macedonia».

(El Aleph, «El Aleph», Vol. I, pág. 627)

Con este nombre juega Borges en dos ocasiones, al bautizar a sendos personajes suyos; el misteriosamente desaparecido David Alexander Glencairn, enviado para imponer el orden en medio de los disturbios de una ciudad musulmana (ElAleph, «El hombre en el umbral», Vol. I, pág. 612), y el enigmático D. Alenjandro Glencoe, presidente de El Congreso en «El libro de arena» («El Congreso», Vol. II, págs. 20-32), muerto y sepultado en Motevideo, en 1914.

¿Que Borges mezcla nombres? ¿Que sólo alcanza a conocer de un modo superficial la cultural arabo-islámica? De ningún modo; y valgan algunos ejemplos como muestra de lo cabal que puede llegar a ser su coriocimiento de la materia:

- En Historia de la eternidad (I, 356), nos sorprende con una certera referencia al libro de Ibn Tufayl, El filósofo autodidacta, cuyo protagonista, Hayy («vivo»), pasar por ser el equivalente árabe al Emilio de Rousseau, habitante de una isla semejante a la que ideara Tomás Moro en su Utopía. Dice así:

«Vivo, Hijo del Despierto, el improbable Robinson metafísico de la novela de Abubeker Abentofail, se resigna a comer aquellas frutas y aquellos peces que abundan en su isla».

- En el mismo libro (cinco páginas después), narra -con todo lujo de detalles- la atemporal peregrinación que -cuenta la tradición islámica- llevó a cabo el profeta Mahoma a lomos de la yegua al-Burâq: 
«Se sabe que el Profeta fue arrebatado hasta el séptimo cielo por la resplandeciente yegua Alburak y que conversó en cada uno con los patriarcas y ángeles que lo habitan y que atravesó la Unidad y sintió un frío que le heló el corazón cuando la mano del Señor le dio una palmada en el hombro. El casco de Alburak, al dejar la tierra, volcó una jarra llena de agua; a su regreso, el profeta la levantó y no se había derramado una sola gota».

- Asimismo, en «La busca de Averroes» (El Aleph, Vol. I, págs. 582-588) narra la refutación que el filósofo cordobés emprendió contra la ópera prima de Al-Gazzalî, apuntando también - del mismo modo certero- la adaptación de la filosofía aristotélica que Averroes llevó a cabo:

«Abulgualid Muhámmad Ibn-Ahmad Ibn-Muhámmad Ibn-Rushd [...] redactaba el undécimo capítulo de la obra Tahafut-ul-Tahafut (Destrucción de la Destrucción), en el que mantiene, contra el asceta persa Ghazali, autor del Tahafut-ul-falasifa (Destrucción de filósofos), que la divinidad sólo conoce las leyes generales del universo, lo concerniente a las especies, no al individuo $[\ldots]$.

La pluma corría sobre la hoja, los argumentos se enlazaban, irrefutables, pero una leve preocupación empañó la felicidad de Averroes. No la causaba el Tahafut, trabajo fortuito, sino un problema de índole filológica vinculado a la obra monumental que lo justificaría entre las gentes: el comentario de Aristóteles. [...] Interpretar sus libros como los ulemas interpretan el Alcorán era el arduo propósito de Averroes».

- Y aún se permite citar unos famosos versos de la poesía andalusí; aquellos en los que el emir Abd al-Rahman, sirio de origen, comparte su nostalgia de Oriente con algo que le trae recuerdos de allá: una palma de los jardines de la Ruzafa:

«Tu también eres, ¡oh palma!

En este suelo extranjera».

(Idem, pág. 587)

- También en el El Aleph («El Aleph», Vol. I, pág. 628), parafrasea al andalusí de origen y padre de la Filosofía de la Historia árabe; Ibn Jaldún:

«La mezquita data del siglo VII; las columnas proceden de otros tiempos de religiones anteislámicas, pues, como ha escrito Abenjaldún: En las repúblicas fundadas por nómadas, es indispensable el concurso de forasteros para todo lo que sea albañilería».

- Incluso llega a demostrar estar al tanto de la labor del insigne arabista español, D. Miguel Asín Palacios; cuya obra, Huellas del Islam, cita con fecha y lugar de edición. (Otras inquisiciones, «Pascal», Vol. I, pág. 705).

Un asiduo visitante de las páginas borgeanas resulta ser Omar Jayyâm, el célebre polígrafo persa autor de las famosas Ruba'iyât, o «cuartetas», -cuyo manuscrito, por cierto, descansa en el fondo del mar junto a los restos del Titanic-. Es el mismo rapsoda 
persa del carpe diem cuyo nombre asocia la historiografía arabo-musulmana con el del visir reformista Nizâm al-Mulk (fundador de la Universidad Nizâmîya), y el de Hasan alSabbâh, («el viejo de la montaña» de Alamut), fundador de la secta de los Asesinos.

A Omar Jayyam (o, según la transcripción inglesa que a veces sigue Borges, Umar Khayyâm), el argentino llega a dedicarle un poema compuesto en cuartetas, y que comienza:

«Torne mi voz la métrica del persa

A recordar que el tiempo es la diversa

Trama de sueños ávidos que somos

Y que el secreto Soñador dispersa».

(Elogio de la sombra, «Rubaiyat», Vol. I, pág. 993)

$Y$ en prosa, el mayor homenaje de Borges al persa es el relato titulado «El enigma de Edward Fitzgerald» (Otras inquisiciones, Vol. I, págs. 688-690), en el que no sólo se acerca a la figura de Omar Jayyam en el contexto de su biografía (A), sino que describe incluso la polémica alzada en torno a la traducción demasiado libre de sus poemas llevada a cabo por Fitzgerald (B):

(A) «Un hombre, Umar ben Ibrahim, nace en Persia, en el siglo XI de la era cristiana (aquel siglo para él el quinto de la Héjira) y aprende el Alcorán y las tradiciones con Hassán ben Sabbáh <sic>, futuro fundador de la secta de los Hashishin o Asesinos, y con Nizam ul-Mulk, que será visir de Alp Arslán, conquistador del Cáucaso».

(pág. 688)

(B) «Swinburne escribe que Fitzgerald «ha dado a Omar Khayyán $<$ sic $>$ un sitio perpetuo entre los mayores poetas de Inglaterra, y Chesterton, sensible a lo romántico y a lo clásico de ese libro sin par, observa que a la vez hay en él «una melodía que se escapa y una inscripción que dura». Algunos críticos entienden que el Omar de Fitzgerald es, de hecho, un poema inglés con alusiones persas; Fitzgerald interpoló, afinó e inventó, pero sus Rubaiyat parecen exigir de nosotros que las leamos como persas $\mathrm{y}$ antiguas».

(págs. 688-689)

Omar Jayyam representa la filosofía y el saber persa; la búsqueda de Dios que Oriente inauguró para la Historia Universal. En uno de sus poemas más bellos («Ajedrez», en $E l$ Hacedor, Vol. I, pág. 813), Borges parafrasea al persa en una feliz comparación del juego del ajedrez con la existencia del hombre y esa búsqueda oriental de Dios:

«...También el jugador es prisionera

(la sentencia es de Omar) de otro tablero

De negras noches y blancos días.

Dios mueve al jugador, y éste, la pieza.

¿Qué dios detrás de Dios la trama empieza.

De polvo y tiempo y sueño y agonías? 
Aún así la búsqueda por excelencia es la de Sindbad, «el otro Ulises»; Simbad el Marino:

«El mar. El joven mar. El mar de Ulises

$\mathrm{Y}$ el de aquel otro Ulises que la gente

Del Islam apodó famosamente

Es-Sindibad del Mar».

(El oro de los tigres, «El mar», Vol. pág. 1118)

Este Simbad, personaje originario del relato persa Sindibâd-nâme, c inmortalizado por su incorporación a las Mil y Una Noches, busca en sus siete viajes(Otras inquisiciones, Vol. I, «The purple land», pág. 733), pero lleva consigo la maldición de sólo buscar, sin encontrar, y sin pertenecer a ningún sitio, como sentencia Borges en un poema a la memoria de Alfonso Reyes:

«Supo bien aquel arte que ninguno

Supo del todo, ni Simbad ni Ulises,

Que es pasar de un país a otros países

y estar íntegramente en cada uno».

(El Hacedor, Vol. I. «In memoriam A.R.», pág. 829)

Pero la gran alegoría persa de J.L. Borges consiste en repetidas referencias a los dos grandes poetas de la mitología sasánida: Abû-1-Qâsim Firdawsî (Firdusi), y Farîd al-Dîn 'Attâr. Con ellos, más que en ninguna otra ocasión, el escalpelo borgeano separa y estirpa para ser repartido posteriormente a todo lo largo de su producción literaria. Hay algo que une a ambos poetas persas, lo que nos hace suponer que fue la búsqueda de referencias a ese algo lo que dio la llave a Borges para ahondar en sus obra: tanto Firdawsî como Attâr dedicaron un espacio de excepción en su mejor obra al pájaro mitológico persa; cl Sîmurg:

«El Sîmurg es un pájaro inmortal que anida en las ramas del Arbol de la Ciencia (...) Firdusi, en el Libro de los reyes, que recopila y versifica antiguas leyendas del Irán, lo hace padre adoptivo de Zal. (...) Farîd al-Dîn Attâr, en el siglo XIII, lo eleva a símbolo o imagen de la divinidad. Esto sucede en el Mantiq al-Tayr (Coloquio de los Pájaros)».

(J.L. Borges, El libro de los Seres Imaginarios, Madrid, Bruguera, 1980, pág. 183)

En efecto, Firdawsî, en su Shahnama («El libro de los Reyes», 60.000 versos, 35 años para componerlos) relata toda la historia mítica y legendaria de Persia hasta la conquista árabe. Según el Shahnama, cuando el Simurg se acerca, el cielo oscurece; y cuenta que Zâl, (hijo de Sâm, hijo éste de Noé) fue raptado recién nacido por el Simurg y criado por éste. Cuando el muchacho fue devuelto a su padre, Simurg dejó con él una pluma que Zâl sólo tenía que quemar para llamarlo. Simurg extendió su protección sobre el hijo de Zâl, Rustâm, héroe del Shahnama.

Y por su parte, 'Attâr, en su Mantiq al-Tayr, refiere que los pájaros, dirigidos por la abubilla, partieron a la búsqueda del Simurg, al que habían elegido para que fuera su rey. 
Todos, excepto treinta, murieron en el camino a través de siete peligrosos valles. Pero los treinta supervivientes, al observar la formación de vuelo que llevaban, se reconocieron en conjunto como la divinidad: (si-murg: Simurg). Habían encontrado lo que buscaban ${ }^{3}$.

Pues bien, con la misma fidelidad que en el Mantiq al-Tayr, lo refiere Borges:

«El remoto rey de los pájaros, el Simurg, deja caer en el centro de la China una pluma espléndida; los pájaros resuelven buscarlos, hartos de su antigua anarquía. Saben que el nombre de su rey quiere decir treinta pájaros; saben que su alcázar está en el Kaf, la montaña circular que rodea la tierra. Acometen la casi infinita aventura; superan siete valles, o mares; el nombre del penúltimo es Vértigo; el último se llama Aniquilación. Muchos peregrinos desertan, otros perecen. Treinta, purificados por los trabajos, pisan la montaña del Simurg. Lo contemplan al fin: perciben que ellos son el Simurg y que el Simurg es cada uno de ellos».

(Historia de la eternidad, «El acercamiento a Almotásim», Vol. I, pág. 418)

- Con el mismo rigor cita el Shahnama de Firdawsî, el «libro de los Reyes» (Discusión, «Nota sobre Walt Whitman», Vol. I, pág. 249) e incluye otras seis referencias más a Farîd al-Dîn 'Attâr'.

«Yo debí estudiar más las literaturas orientales», afirma aún Jorge Luis Borges ${ }^{5}$ con una modestia capaz de ruborizar al especialista. ¿Cómo explicar, pues, tanta referencia, tal capacidad de síntesis y tal precisión en la cita? En la misma línea nos explica la clave: «Pero he sentido el golpe, el impacto de la belleza». Bendito impacto que le ofreció las palabras con que cierra las presente líneas:

EI Islam, que fue espadas

que desolaron el poniente y la aurora

y estrépito de ejércitos en la tierra

y una revelación y una disciplina

y la aniquilación de los ídolos

y la conversión de todas las cosas

3 Cfr. Enciclopedy of Islam, s.v. "Firdawsî» (Vol. III, págs. 110-111) y s.v. "Attâr» (Vol. I, pág. 513).

4 Discusión, Vol. I, «Nota sobre Walta Whitman», págs. 251, 256.

Otras inquisiciones, Vol. I, «Sobre Chesterton», pág. 695.

El oro de los tigres, Vol. I, «Los cuatro cielos», pág. 1.128.

La rosa profunda, Vol. II, «The unending rose», pág. 116.

Cfr. especialmente, en Nueve ensayos dantescos. Vol. II, el relato «El Simurgh y el águila», págs. 366-368.

s Siete noches, Vol. II, «la poesía», pág. 264. 
en un terrible Dios, que está solo,

y la rosa y el vino del sufí

y la rimada prosa alcoránica

y ríos que repiten alminares

y el idioma infinito de la arena

y ese otro idioma, el álgebra,

y ese largo jardín, Las Mil y Una Noches,

y hombres que comentaron a Aristóteles

y dinastías que son ahora nombres del polvo...

(Jorge Luis Borges, La cifra, II «Ronda», pág. 293) 